\title{
Avaliação das propriedades da blenda de poli(3-hidroxibutirato)/quitosana após esterilização térmica ou radiolítica
}

\section{Evaluation of the properties poly(3-hidroxybutyrate)/ chitosan blend after radiolytic or thermal sterilization}

\author{
Grasielly Souza', Andrelina Santos ${ }^{1}$ e Glória Vinhas ${ }^{\text {* }}$ \\ 'Laboratório de Materiais Poliméricos e Caracterização - LMPC, Departamento de Engenharia Química, \\ Universidade Federal de Pernambuco - UFPE, Recife, PE, Brasil \\ *gmvinhas@yahoo.com.br
}

\begin{abstract}
Resumo
Nesse trabalho foi desenvolvido filme de PHB/quitosana com aplicação promissora em embalagens de alimentos e medicamentos. Esses filmes foram preparados via casting solution e após esterilização térmica ou radiolítica suas propriedades foram avaliadas a partir da microscopia eletrônica de varredura, ensaio de tração, calorimetria exploratória diferencial e análise termogravimétrica. Foram constatadas alterações na morfologia dos filmes de PHB/quitosana após os processos de esterilização. As propriedades mecânicas da blenda se mantiveram aproximadamente constantes após esterilização térmica. Porém, após irradiação as blendas apresentaram-se quebradiças. As propriedades térmicas da blenda foram alteradas apenas para as doses de 50 e $75 \mathrm{kGy}$, em que foi observado uma redução no valor da entalpia de cristalização, grau de cristalinidade, cristalinidade relativa e taxa de cristalização da blenda. Foi observado que a degradação térmica dos filmes de PHB e das blendas, antes e após os processos de esterilização apresentaram um único estágio $\left(250-300^{\circ} \mathrm{C}\right)$.
\end{abstract}

Palavras-chave: blendas poliméricas, esterilização térmica, esterilização radiolitica, PHB, quitosana.

\begin{abstract}
In this work was developed PHB/chitosan film with promising application in food and medicine packaging. These films were prepared by the casting solution and after radiolytic or thermal sterilization their properties were evaluated by scanning electron microscopy, tensile testing, differential scanning calorimetry and thermogravimetric analysis. $\mathrm{PHB} /$ chitosan films changed their morphology after sterilization processes. Mechanical properties of the blend remained approximately constant after thermal sterilization. But, after irradiation the blends presented brittle. Thermal properties of the blend were changed only for the doses of 50 and $75 \mathrm{kGy}$, in which case was observed a reduction in the crystallization enthalpy value, the degree of crystallinity, relative crystallinity and crystallization rate of the blend. It was observed thermal degradation of the PHB films and blends, before and after sterilization processes presented a single stage $\left(250-300^{\circ} \mathrm{C}\right)$.
\end{abstract}

Keywords: polymers blends, thermal sterilization, radiolytic sterilization, PHB, chitosan.

\section{Introdução}

Os produtos fabricados a partir de materiais plásticos têm estado cada vez mais presentes no cotidiano das pessoas. Isso se deve a algumas propriedades desses materiais, como leveza, atoxicidade, durabilidade, baixo custo, capacidade de serem reciclados, de serem moldados e de substituir produtos feitos de metais, madeira, vidro, papel, entre outros. Além disso, apresentam uma variedade de aplicações, desde plásticos rígidos altamente cristalinos a polímeros dúcteis ${ }^{[1,2]}$.

Em contrapartida, o crescente uso desses produtos e seu descarte incorreto têm provocado uma série de danos ao meio ambiente, uma vez que, os mesmos são produzidos a partir de polímeros sintéticos convencionais, bastante resistentes ao ataque de micro-organismos, e, portanto, levam mais tempo para se degradarem, contribuindo assim para o aumento da quantidade de resíduos plásticos presentes no meio ambiente ${ }^{[3]}$. Com a finalidade de minimizar o impacto ambiental causado pelo mau gerenciamento de resíduos plásticos, tem-se como principais alternativas: a incineração, a reciclagem ou a substituição dos polímeros sintéticos convencionais por polímeros biodegradáveis ${ }^{[4,5]}$.

Os polímeros biodegradáveis são consumidos em semanas ou meses, sob condições favoráveis, pela ação de 
micro-organismos de ocorrência natural como bactérias, fungos e algas, resultando em dióxido de carbono $\left(\mathrm{CO}_{2}\right)$, metano $\left(\mathrm{CH}_{4}\right)$, componentes celulares e outros produtos ${ }^{[2,6]}$. Os polímeros biodegradáveis podem ser provenientes de fontes naturais renováveis como milho, celulose, batata, cana de açúcar, ou serem sintetizados por bactérias como é o caso do poli(3-hidroxibutirato) (PHB), ou ainda, podem ser derivados de fonte animal, como a quitosana que é produzida a partir da carapaça de alguns crustáceos e também está presente em alguns insetos, fungos, cogumelos e minhocas ${ }^{[7-9]}$.

Muitos pesquisadores vêm se dedicando ao estudo da modificação dos polímeros biodegradáveis para viabilizar o seu processamento e ampliar sua aplicabilidade. Para isso, blendas, compósitos e nanocompósitos estão sendo desenvolvidos ${ }^{[1,10-13]}$. Além disso, os polímeros biodegradáveis estão sendo cada vez mais utilizados em aplicações médico-hospilares ou alimentícias. Porém, esses setores necessitam que seus produtos estejam estéreis, portanto tornar-se importante avaliar e relatar as possíveis degradações sofridas por estes materiais após processos de esterilização.

Por esse motivo, o objetivo principal desse trabalho foi ampliar os estudos dos polímeros biodegradáveis, avaliando a estabilidade térmica ou radiolítica da blenda PHB/quitosana destinadas para aplicações médico-hospitalares ou alimentícias. A escolha do PHB está relacionada com suas propriedades semelhantes ao polipropileno (PP), já a quitosana por ser um polímero que apresenta atividade antimicrobiana, biocompatibilidade e baixa toxicidade ${ }^{[7,14]}$.

\section{Experimental}

\subsection{Materiais}

O PHB utilizado foi fornecido pela PHB Industrial $\mathrm{S} / \mathrm{A}$ e a quitosana comercial de massa molar média com grau de desacetilação de $75-85 \%$ utilizada foi da marca Sigma-Aldrich. O clorofórmio e o ácido acético utilizados foram da marca Vetec e Quimex, respectivamente.

\subsection{Preparação dos filmes poliméricos}

Os filmes foram obtidos utilizando a técnica solution casting.

\subsubsection{Filme de PHB puro}

$\mathrm{O} P H B$ foi peneirado e a granulometria utilizada variou entre 50 e 100 mesh. A solução de PHB foi obtida dissolvendo-se 1,3 g do polímero em $50 \mathrm{~mL}$ de clorofórmio, num béquer de $250 \mathrm{~mL}$. A solução foi agitada por 3 horas em agitador magnético a $60{ }^{\circ} \mathrm{C}$. Após agitação, a solução foi deixada em repouso por 48 horas para que o PHB intumescesse. Após o tempo de 48 horas, a solução de PHB foi agitada em homogeneizador Turratec TE-102 por 15 minutos e foi filtrada utilizando chumaço de algodão para retirar possíveis impurezas da solução. Após a filtração, a solução foi vertida em placa de petri de vidro ( $20 \mathrm{~cm}$ de diâmetro) e os filmes foram secos em uma sala cuja temperatura ambiente era em torno de $30^{\circ} \mathrm{C}$. A proporção de massa de solução de polímero por $\mathrm{cm}^{2}$ de placa utilizada na produção dos filmes foi de $0,24 \mathrm{~g} / \mathrm{cm}^{2}$.

\subsubsection{Filme de quitosana pura}

A solução de quitosana foi obtida dissolvendo-se $1,0 \mathrm{~g}$ de quitosana em $100 \mathrm{~mL}$ de solução de ácido acético $(0,5 \% \mathrm{v} / \mathrm{v})$ em um Erlenmeyer de $250 \mathrm{~mL}$. A solução foi agitada em agitador magnético, a temperatura ambiente $\left(\sim 25^{\circ} \mathrm{C}\right)$ até completa solubilização. A solução foi vertida em placa de petri de vidro e os filmes foram secos em estufa a aproximadamente $40^{\circ} \mathrm{C}$. A proporção de massa de solução de polímero por $\mathrm{cm}^{2}$ de placa utilizada na produção dos filmes foi de $0,32 \mathrm{~g} / \mathrm{cm}^{2}$.

\subsubsection{Blenda PHB/quitosana}

As soluções de PHB e quitosana foram preparadas separadamente como descritas nos itens anteriores. A blenda foi obtida de modo que a concentração de quitosana fosse $0,7 \%(\mathrm{~m} / \mathrm{m})$, para isso foi adicionada $1 \mathrm{~mL}$ da solução de quitosana a $50 \mathrm{~mL}$ da solução de PHB e a solução resultante foi agitada por 15 minutos em homogeneizador Turratec TE-102. A solução final foi vertida em placa de petri de vidro e os filmes foram secos em uma sala cuja temperatura ambiente era de aproximadamente $30^{\circ} \mathrm{C}$. A proporção de massa de solução de polímero por $\mathrm{cm}^{2}$ de placa utilizada na produção dos filmes foi de $0,24 \mathrm{~g} / \mathrm{cm}^{2}$.

\subsection{Esterilização térmica}

Os filmes de PHB puro, de quitosana pura e as blendas de $\mathrm{PHB}$ /quitosana foram submetidos à esterilização térmica em autoclave modelo 415 Fanem. O processo consistiu na obtenção de vapor a temperatura de $121{ }^{\circ} \mathrm{C}$, sob pressão de $1 \mathrm{~atm}$. Nestas condições, os filmes foram mantidos por 15 minutos. Após o tempo de esterilização, os filmes foram resfriados.

\subsection{Esterilização radiolítica}

Os filmes de PHB puro, quitosana pura e as blendas de $\mathrm{PHB} /$ quitosana foram irradiados à temperatura ambiente $\left(\sim 25^{\circ} \mathrm{C}\right)$ nas doses de 25,50 e $75 \mathrm{kGy}$. A irradiação foi realizada com raios gama provenientes de uma fonte ${ }^{60} \mathrm{Co} \mathrm{em}$ equipamento "Gammacell”, modelo GC 220, localizado no Departamento de Energia Nuclear (DEN) da Universidade Federal de Pernambuco.

\subsection{Técnicas de caracterização}

\subsubsection{Microscopia eletrônica de varredura (MEV)}

Os filmes de PHB puro e as blendas de PHB/Quitosana, antes e após esterilização térmica ou radiolítica, foram analisados em microscópio eletrônico de varredura (MEV) Shimadzu SS-550 Superscan. As amostras foram metalizadas com uma fina camada de ouro, utilizando fita de carbono como suporte antes de serem escaneadas.

\subsubsection{Ensaio mecânico de tração}

Os ensaios de tração dos filmes de PHB puro, quitosana pura e da blenda $\mathrm{PHB}$ /quitosana, antes e após esterilização térmica ou radiolítica, foram realizados em triplicata e conduzidos em máquina universal, marca EMIC seguindo a norma ASTM D-882 ${ }^{[15]}$, a temperatura ambiente $\left(\sim 25^{\circ} \mathrm{C}\right)$ e sem controle de umidade, nas seguintes condições: 
velocidade da garra: $5 \mathrm{~mm} / \mathrm{min}$, distância inicial entre as garras: $40 \mathrm{~mm}$, dimensão do corpo de prova: $2,5 \times 7,5 \mathrm{~cm}$.

\subsubsection{Análise Termogravimétrica (TGA)}

As amostras de PHB puro, de quitosana pura e de PHB/quitosana, antes e após esterilização térmica ou radiolítica, foram submetidas a testes termogravimétricos para obtenção das faixas de perda de massa. Foi utilizada uma termobalança Perkin Elmer, modelo STA 6000. Os testes foram realizados com taxa de aquecimento de $10{ }^{\circ} \mathrm{C} / \mathrm{min}$, sob atmosfera de nitrogênio (fluxo: $20 \mathrm{~mL} / \mathrm{min}$ ), em uma faixa de temperatura de $50-600{ }^{\circ} \mathrm{C}$.

\subsubsection{Calorimetria Exploratória Diferencial (DSC)}

As amostras dos filmes de PHB puro e das blendas PHB/quitosana, antes e após processos de esterilização térmica ou radiolítica, foram caracterizadas por calorimetria exploratória diferencial (DSC), em equipamento da marca Mettler Toledo, modelo DSC 1 STAR $^{\mathrm{e}}$ SYSTEM, utilizando cadinho de alumínio sob atmosfera de nitrogênio (fluxo: $50 \mathrm{~mL} / \mathrm{min}$ ) com massa entre 4 e $10 \mathrm{mg}$.

Todos os testes foram conduzidos em três estágios: aquecimento de $25^{\circ} \mathrm{C}$ a $185^{\circ} \mathrm{C}$, a uma taxa de aquecimento de $30{ }^{\circ} \mathrm{C} / \mathrm{min}$, resfriamento até $25{ }^{\circ} \mathrm{C}$, a uma taxa de resfriamento de $16{ }^{\circ} \mathrm{C} / \mathrm{min}$ e reaquecimento até $185^{\circ} \mathrm{C}$, a uma taxa de aquecimento de $30^{\circ} \mathrm{C} / \mathrm{min}$. A partir deste método foi possível obter a temperatura de fusão $\left(\mathrm{T}_{\mathrm{m}}\right)$, temperatura de cristalização $\left(\mathrm{T}_{\mathrm{c}}\right)$ e entalpia de cristalização $\left(\Delta \mathrm{H}_{\mathrm{c}}\right)$.

A cristalinidade relativa (x), o grau de cristalinidade (Xc), a taxa de cristalização (c) e a entalpia de cristalização $\left(\Delta \mathrm{H}_{\mathrm{c}}\right)$ foram calculadas utilizando o software INTEGRAL ${ }^{\mathrm{TM}}$, desenvolvido na UFCG. As fórmulas matemáticas utilizadas no programa para obtenção destes parâmetros estão apresentadas nas Equações 1, 2, 3 e 4, respectivamente.

$x=\frac{1}{E_{0}} \int_{t_{1}}^{t}\left|J\left(t^{\prime}\right)-J_{0}\left(t^{\prime}\right)\right| d t^{\prime}, E_{0}=\int_{t_{1}}^{t_{2}}\left|J(t)-J_{0}(t)\right| d t$

$X_{C}=\frac{E_{0}}{w_{p} \Delta H_{m}^{\circ}}$

$c=\frac{d x}{d t}=\frac{1}{E_{0}}\left|J(t)-J_{0}(t)\right|$
$\Delta H_{c}=\frac{E_{0}}{m_{s}}$

Onde J é o fluxo de calor medido no DSC, $\mathrm{J}_{0}$ é a linha de base virtual durante o evento de cristalização, $t_{1}$ e $t_{2}$ são os tempos inicial e final do evento, respectivamente, $\mathrm{E}_{0}$ é o calor latente de mudança de fase, $\mathrm{w}_{\mathrm{p}}$ é a fração mássica do PHB na amostra, $\mathrm{m}_{\mathrm{s}}$ é a massa da amostra e $\Delta \mathrm{H}_{\mathrm{m}}{ }^{\circ}$ é o calor latente de fusão por unidade de massa do PHB 100\% cristalino, que é $146 \mathrm{~J} / \mathrm{g}$ de acordo com a literatura ${ }^{[16]}$.

\section{Resultados e Discussão}

\subsection{Filmes poliméricos}

A Figura 1 mostra os filmes de PHB puro, quitosana pura e da blenda $\mathrm{PHB} /$ quitosana estudadas neste trabalho. Os filmes de PHB puro apresentaram-se homogêneos, opacos e sua espessura média foi de $0,07 \pm 0,02 \mathrm{~mm}$. Os filmes de quitosana pura apresentaram-se homogêneos, transparentes e sua espessura média foi de $0,06 \pm 0,03 \mathrm{~mm}$. As blendas de PHB/quitosana apresentaram-se homogêneas, opacas e sua espessura média foi de $0,08 \pm 0,01 \mathrm{~mm}$.

\subsection{Avaliação das propriedades físicas das blendas e dos polímeros puros}

\subsubsection{Propriedades morfológicas}

A morfologia da superfície dos filmes foi estudada por MEV, como mostra a Figura 2. O filme de PHB puro apresentou uma superfície rugosa e irregular (Figura 2a), morfologia semelhante foi também constatada por Abdelwahab et al. ${ }^{[10]}$. Com a adição da quitosana, os filmes apresentaram mudanças em suas características morfológicas. Foram observados grânulos de diferentes diâmetros (Figura 2b) que podem ser associados à presença da quitosana. A formação desses grânulos possivelmente foi devido a imiscibilidade da solução de quitosana em água na solução de PHB em clorofórmio.

A superfície da blenda após processo de esterilização térmica (Figura 3a) apresentou-se rugosa e irregular com a presença de grânulos (quitosana) de diâmetros menores comparados a blenda antes da esterilização térmica, também foi observado a presença de alguns vazios na matriz. Já os filmes irradiados a $25 \mathrm{kGy}$ (Figura 3b) apresentaram-se lisos e homogêneos.

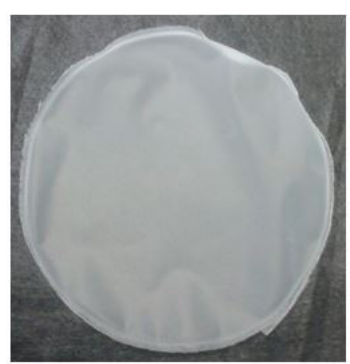

(a)

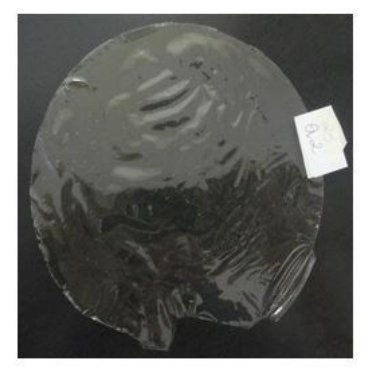

(b)

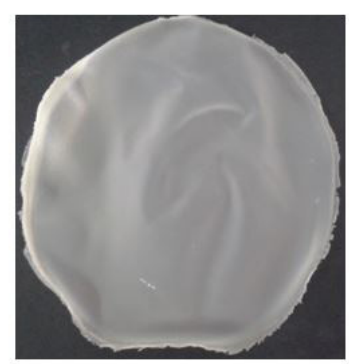

(c)

Figura 1. Filmes de PHB puro (a), de quitosana pura (b) e a blenda PHB/quitosana (c). 


\subsubsection{Propriedades mecânicas}

Foram realizados testes de resistência à tração para os filmes de $\mathrm{PHB}$ puro, $\mathrm{PHB} /$ quitosana e quitosana pura antes e após processos de esterilização térmica ou radiolítica. As propriedades mecânicas avaliadas neste trabalho
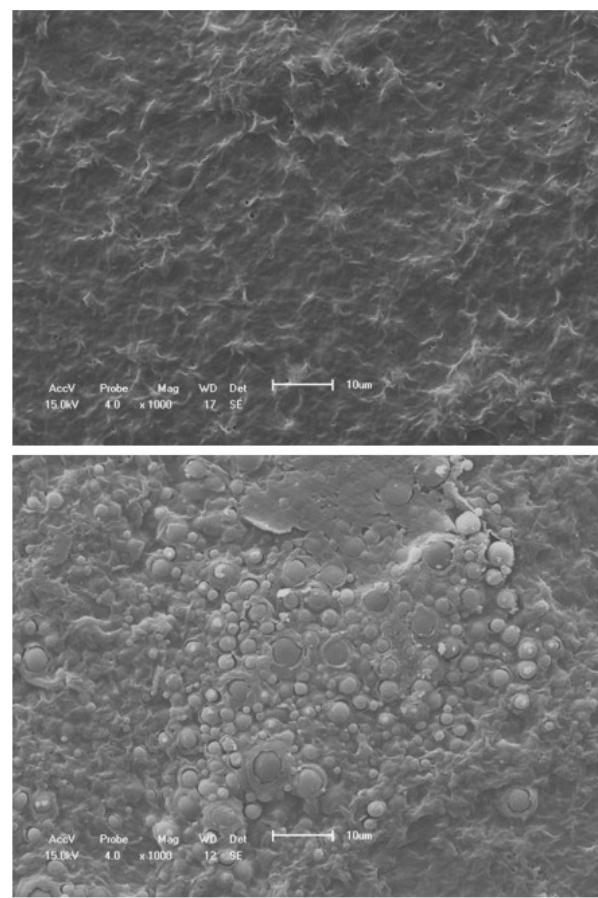

(b)

Figura 2. Micrografia dos filmes de PHB puro (a) e da blenda PHB/quitosana (b) com ampliação de 1000x.
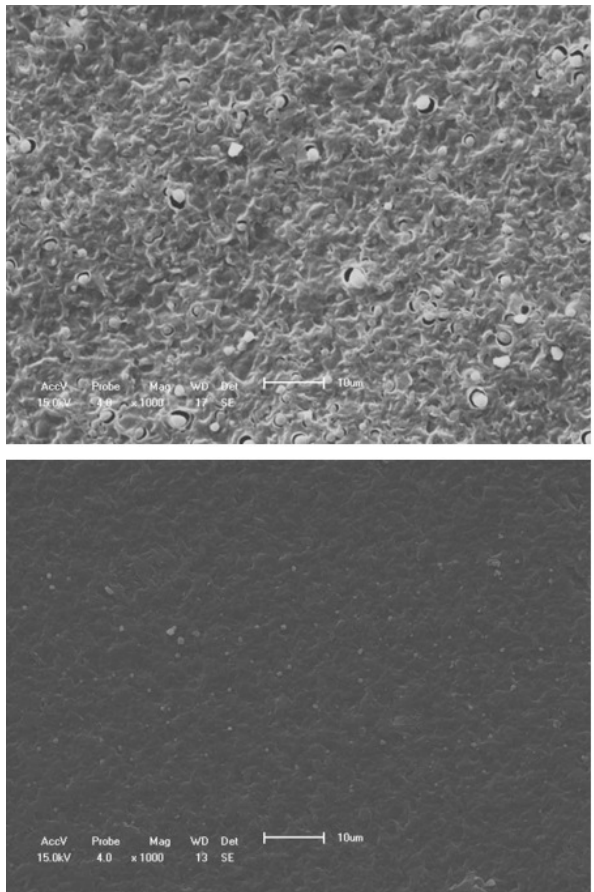

Figura 3. Micrografia dos filmes de PHB/quitosana esterilizado termicamente (a) e a 25 kGy (b) com ampliação de 1000x. foram tensão máxima, deformação específica e módulo de elasticidade.

A partir das Figuras 4, 5 e 6, é possível observar que as propriedades mecânicas dos filmes de quitosana após esterilização térmica diminuem drasticamente. Isso comprovou a alta sensibilidade térmica da quitosana que também foi observada por Corazzari et al. ${ }^{[17]}$. Apesar das grandes variações das propriedades mecânicas dos filmes de quitosana pura, após processo de esterilização térmica, as blendas mostraram-se mais estáveis, variando pouco as suas propriedades. Para a tensão máxima, o filme de quitosana pura sofreu uma redução de $92,4 \%$ nessa propriedade, enquanto a blenda praticamente não sofreu alteração. Para a deformação específica, o filme de quitosana pura sofreu uma redução de $62,5 \%$, enquanto a blenda se manteve praticamente constante. Já para o módulo de elasticidade, essa redução foi de $63,4 \%$ para o filme de quitosana pura e $13,6 \%$ para a blenda. Esses fatos mostraram que a presença da quitosana não comprometeu as propriedades mecânicas estudadas da blenda após processo de esterilização térmica, isso faz com que este material seja promissor para possíveis aplicações médico-hospitalares ou alimentícias.

Pelo teste de Duncan, os filmes de PHB puro e a blenda não esterilizada não diferiram significativamente as propriedades mecânicas estudadas. O mesmo ocorreu para os filmes de PHB puro e a blenda esterilizada termicamente. Comparando os filmes de PHB puro e a blenda antes e após esterilização térmica, pode-se afirmar que não houve alterações significativas em suas propriedades, já os filmes de quitosana sofreram alterações significativas. Todos os testes foram realizados ao nível de 5\% de significância.

As Figuras 7, 8 e 9 mostram uma comparação entre as propriedades mecânicas dos filmes de quitosana pura antes e após esterilização radiolítica. Foi observada uma queda brusca em suas propriedades mecânicas (tensão máxima e módulo de elasticidade), exceto a deformação específica que se manteve praticamente constante. Embora a deformação específica tenha variado pouco (Figura 8), um fato positivo foi a diminuição do desvio das amostras com o aumento da dose de radiação, o que supostamente indica uma maior homogeneidade das mesmas. Caso semelhante foi observado para o módulo de elasticidade (Figura 9).

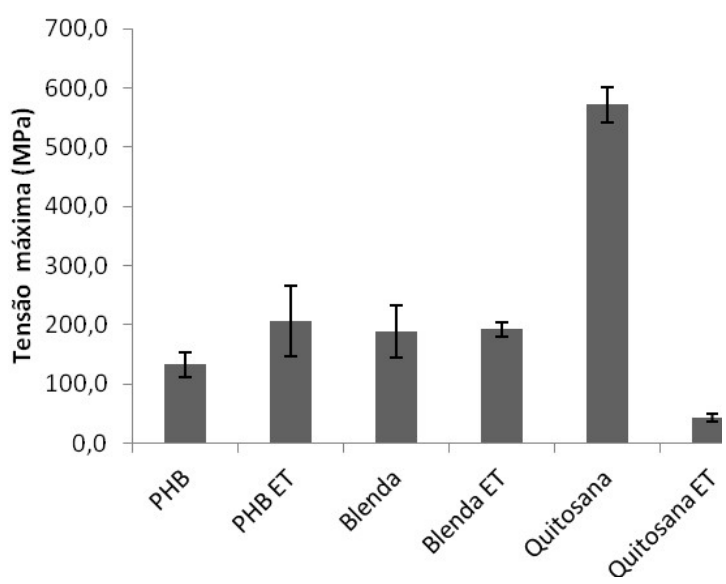

Figura 4. Gráfico da tensão máxima $\times$ amostras dos filmes antes e após processo de esterilização térmica (ET). 


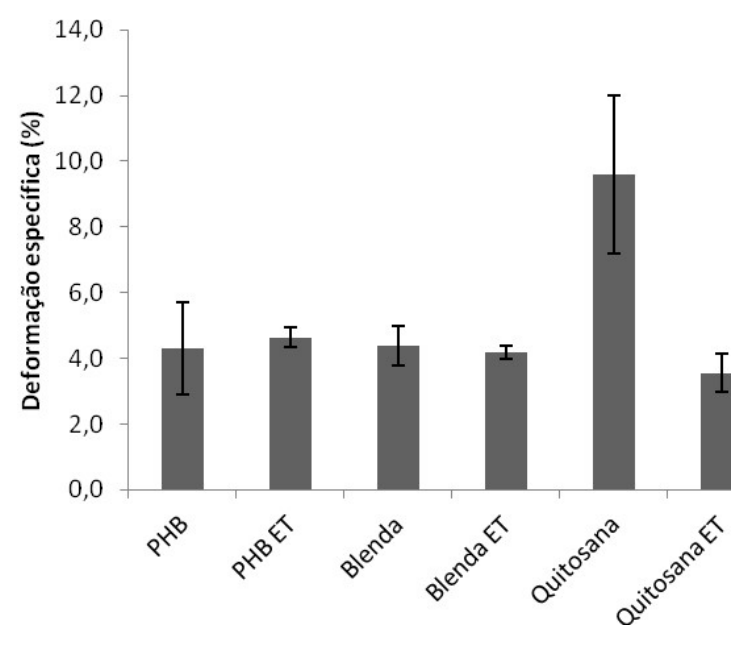

Figura 5. Gráfico da deformação específica $\times$ amostras dos filmes antes e após processo de esterilização térmica (ET).

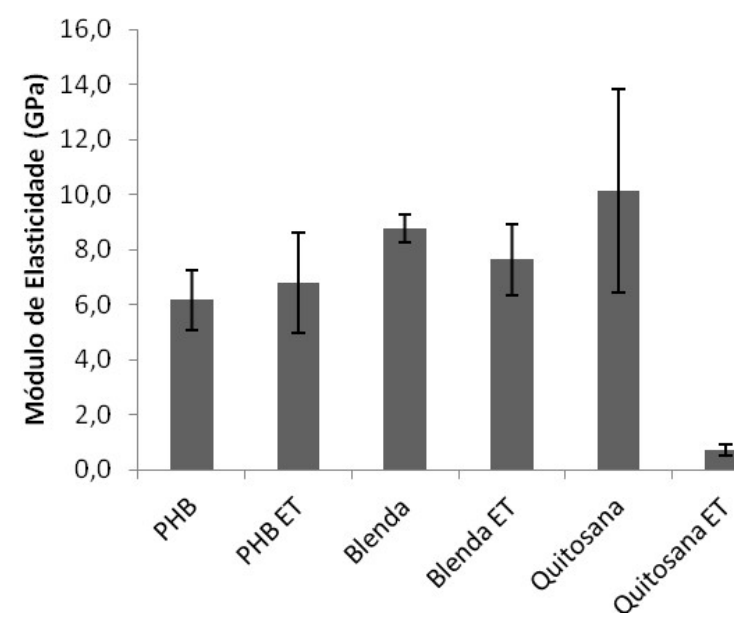

Figura 6. Gráfico do módulo de elasticidade $\times$ amostras dos filmes antes e após processo de esterilização térmica (ET).

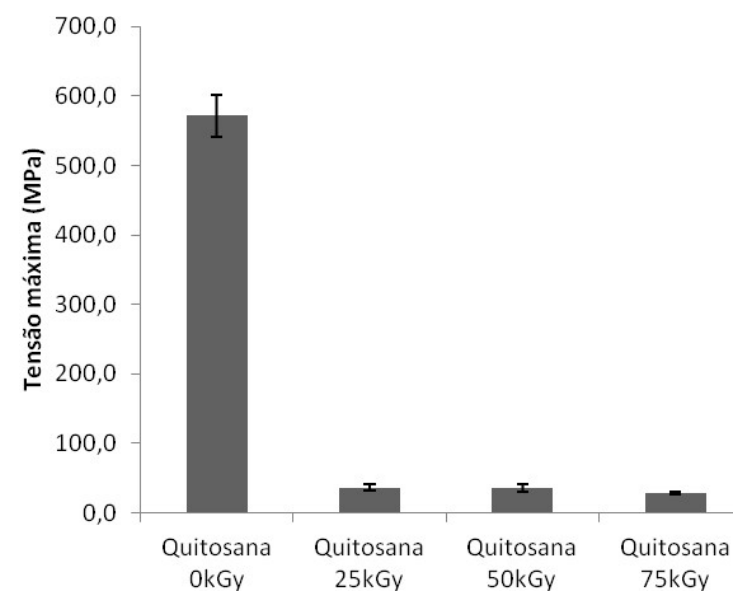

Figura 7. Gráfico da tensão máxima $\times$ amostras dos filmes de quitosana pura não irradiada e irradiada.
Pelo teste de Duncan, é possível afirmar que não houve diferença significativa para as amostras esterilizadas por radiação gama, independentemente da dose utilizada. Porém, houve uma diferença significativa entre os filmes de quitosana pura não esterilizado e esterilizado por radiação gama para a tensão máxima e para o módulo de elasticidade ao nível de 5\% de significância. Já para a deformação específica não há uma alteração significativa.

Não foi possível realizar os ensaios mecânicos dos filmes de PHB puro e das blendas após esterilização radiolítica, pois esses se apresentaram altamente quebradiços. Esse fato é um forte indício de que houve degradação do material após irradiação.

\subsubsection{Propriedades térmicas}

\subsubsection{Calorimetria Exploratória Diferencial (DSC)}

A Figura 10 mostra o fluxo de calor no DSC em função do tempo, no intervalo do teste $0-21$ minutos para o PHB puro e para a blenda $\mathrm{PHB}$ /quitosana antes e após esterilização térmica ou radiolitica. Pode-se observar quatro eventos de mudança de fase: fusão (F1) da fração cristalina, com pico duplo, durante o primeiro aquecimento, cristalização a

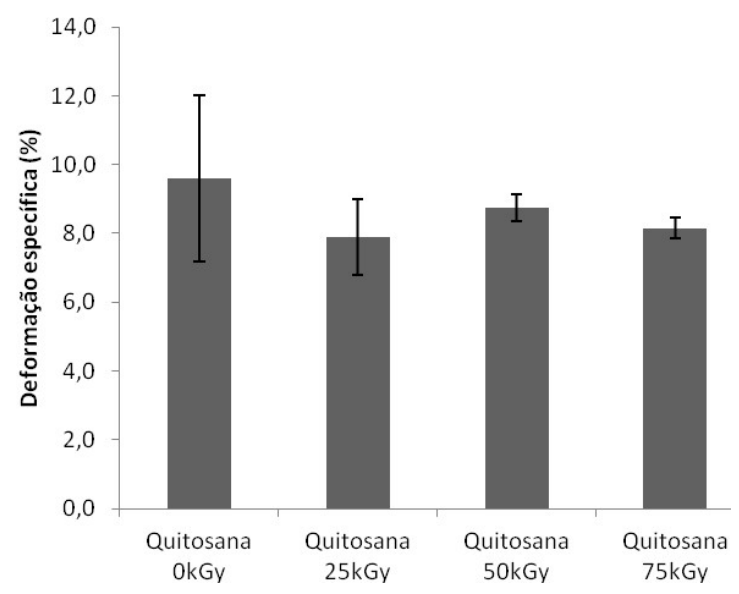

Figura 8. Gráfico da deformação específica $\times$ amostras dos filmes de quitosana pura não irradiada e irradiada.

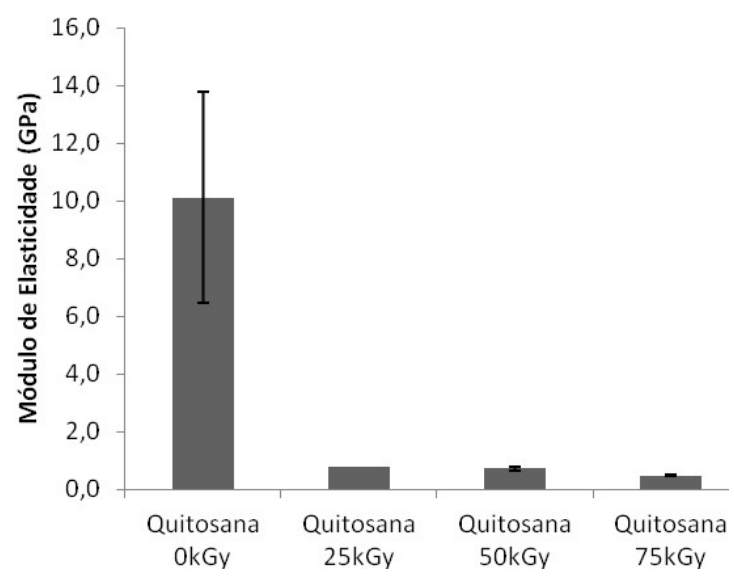

Figura 9. Gráfico do módulo de elasticidade $\times$ amostras dos filmes de quitosana pura não irradiada e irradiada. 
partir do fundido $(\mathrm{C} 1)$ durante o resfriamento, cristalização a frio $(\mathrm{C} 2)$ e segunda fusão (F2) durante o reaquecimento. Esses eventos também foram observados por Machado et al. ${ }^{[18]}$. A cristalização a frio apenas é observada para as blendas irradiadas nas doses de 50 e 75 kGy. Com a adição da quitosana na matriz do PHB percebe-se que não houve uma modificação na cristalinidade deste, pois o grau de cristalinidade, a temperatura e a entalpia de cristalização não apresentaram diferenças significativas em relação ao

Tabela 1. Parâmetros do DSC dos filmes de PHB puro e PHB/ quitosana.

\begin{tabular}{lcccc}
\hline \multicolumn{1}{c}{ Amostras } & $\mathbf{T c}\left({ }^{\circ} \mathbf{C}\right)$ & $\mathbf{T m}\left({ }^{\circ} \mathbf{C}\right)$ & $\Delta \mathbf{H c}(\mathbf{J} / \mathbf{g})$ & $\mathbf{X c}(\%)$ \\
\hline PHB pó & 114 & 170 & 66,35 & 45,45 \\
PHB puro & 113 & 167 & 68,43 & 46,87 \\
Blenda & 110 & 166 & 67,39 & 46,16 \\
Blenda ET & 113 & 165 & 70,35 & 48,19 \\
Blenda 25 kGy & 114 & 165 & 66,81 & 45,76 \\
Blenda 50 kGy & $72 / 61$ & 166 & 37,27 & 25,53 \\
Blenda 75 kGy & $71 / 57$ & 164 & 25,27 & 17,31 \\
\hline
\end{tabular}

ET - Esterilizado termicamente.

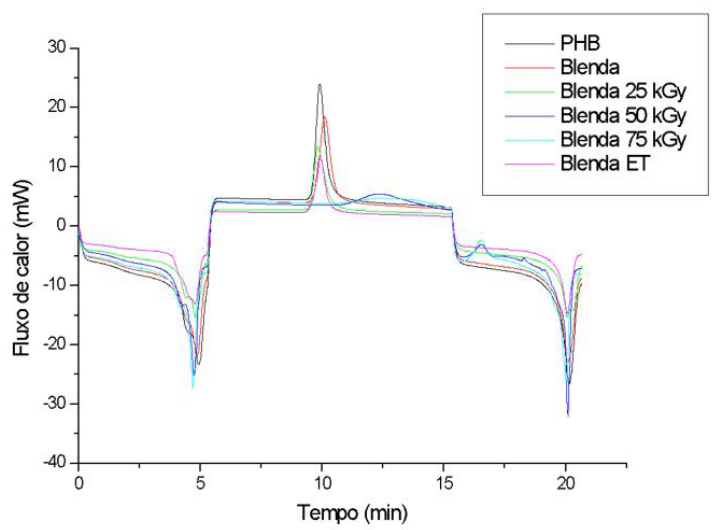

Figura 10. Fluxo de calor em função do tempo para o filme de PHB puro e para a blenda $\mathrm{PHB} /$ quitosana antes e após esterilização térmica $(\mathrm{ET})$ ou radiolítica.

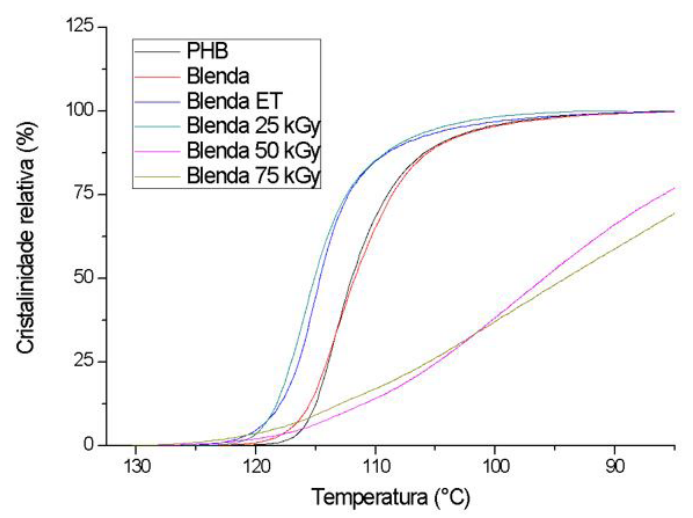

Figura 11. Cristalinidade relativa do filme de PHB puro e da blenda $\mathrm{PHB} /$ quitosana antes e após esterilização térmica ou radiolítica. filme de PHB puro (Tabela 1). Esse resultado também foi observado por Matet et al. ${ }^{[13]}$ que comprovaram que baixos percentuais de quitosana $(2,5$ e $10 \%)$ na blenda $\mathrm{PE} /$ quitosana não alterou a temperatura de cristalização e fusão.

As temperaturas características (cristalização e fusão), a entalpia de cristalização e porcentagem de cristalização obtidas por DSC estão relatadas na Tabela 1. A temperatura de cristalização e fusão do filme de PHB puro são, respectivamente, 113 e $167^{\circ} \mathrm{C}$, que é praticamente a mesma do PHB em pó (Tabela 1) e estas temperaturas estão de acordo com as encontradas na literatura ${ }^{[10,18]}$. A esterilização térmica e a irradiação a 25 kGy não alteraram significativamente a temperatura de cristalização (Tc), a temperatura de fusão $(\mathrm{Tm})$, entalpia de cristalização $(\Delta \mathrm{Hc})$ e o grau de cristalinidade (Xc) deste material. Porém, as blendas esterilizadas a 50 e 75 kGy apresentaram dois picos de cristalização que refere-se à cristalização a frio e no estado fundido, também apresentaram uma diminuição nos valores de entalpia de cristalização e grau de cristalinidade em relação aos outros filmes. Provavelmente, essas doses de radiação gama comprometeram a região cristalina da blenda ${ }^{[19]}$.

A Figura 11 mostra as curvas de cristalinidade relativa, $\mathrm{x}$, ou seja, a fração de material cristalizada, para o filme de PHB puro e para a blenda PHB/quitosana antes e após esterilização térmica ou radiolítica. Para o filme de PHB puro e para a blenda $\mathrm{PHB} /$ quitosana não esterilizada, o processo de cristalização é iniciado praticamente na mesma temperatura, aproximadamente $120^{\circ} \mathrm{C}$, já para as blendas esterilizadas termicamente ou irradiadas na dose de $25 \mathrm{kGy}$ percebe-se que o processo de cristalização ocorre em temperaturas mais altas. Para a indústria, isso significa que durante o resfriamento do material polimérico processado ocorrerá uma cristalização antecipada. As blendas que foram esterilizadas na dose de 50 e $75 \mathrm{kGy}$, percebe-se que a fração de material que cristaliza apresentam um perfil próximo da linearidade, ou seja, as blendas esterilizadas nessas doses apresentam uma faixa de temperatura maior para finalizar a cristalização.

Quando se avalia a taxa de cristalização $\left(\mathrm{min}^{-1}\right)$ (Figura 12), a cristalização do filme de PHB puro é mais rápida do que a cristalização das blendas, principalmente em relação a blenda

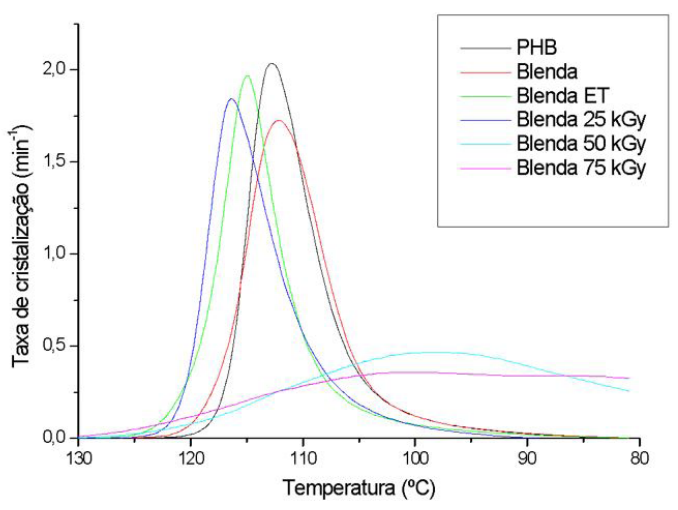

Figura 12. Taxa de cristalização em função da temperatura para o filme de PHB puro e para as blendas de PHB/quitosana antes e após esterilização térmica ou radiolítica. 


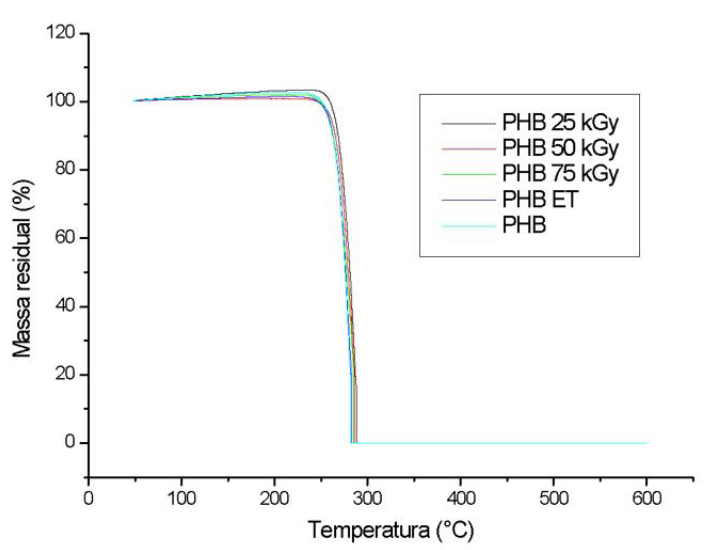

Figura 13. Curvas de TGA para os filmes de PHB puro antes e após processos de esterilização térmica (ET) ou radiolítica.

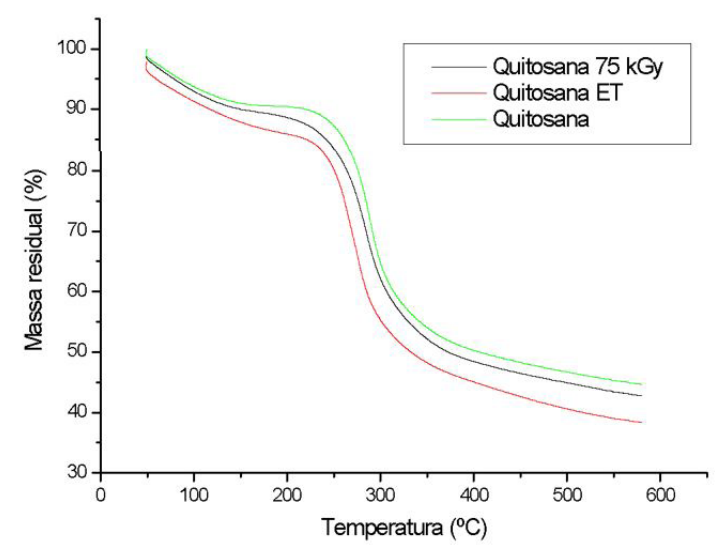

Figura 14. Curvas de TGA para os filmes de quitosana pura antes e após processos de esterilização térmica (ET) ou radiolítica.

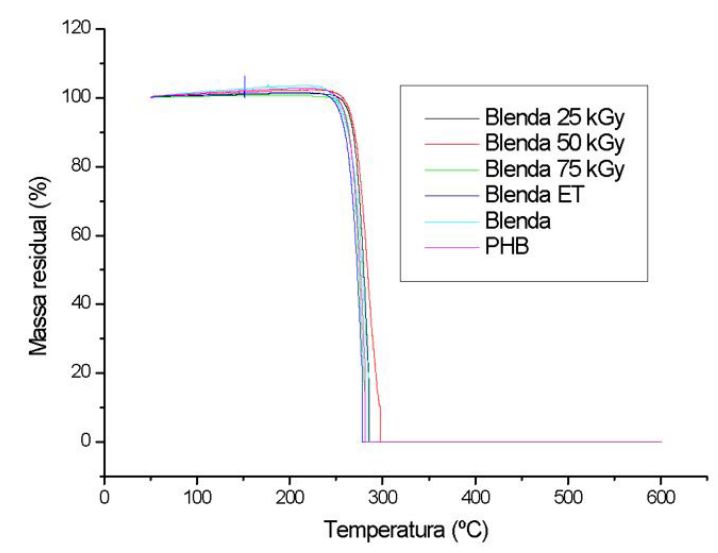

Figura 15. Curvas de TGA para as blendas PHB/quitosana antes e após processos de esterilização térmica (ET) ou radiolítica. não esterilizada. É notório a influência da radiação gama nas doses de 50 e $75 \mathrm{kGy}$ na blenda referente a cristalinidade relativa e a taxa de cristalização. Na Figura 12, observa-se uma lenta cristalização dessas blendas, com intervalo maior de temperatura, além disso a taxa de cristalização máxima é muito baixa quando comparada com os demais filmes.

\subsubsection{Análise termogravimétrica (TGA)}

A degradação térmica dos filmes de PHB puro antes e após esterilização térmica ou radiolítica está apresentada na Figura 13. As análises termogravimétricas dos filmes de PHB puro mostraram degradação total em um único estágio entre 250 e $300^{\circ} \mathrm{C}$.

As análises termogravimétricas dos filmes de quitosana pura antes e após processos de esterilização térmica ou radiolítica estão apresentadas na Figura 14. A degradação térmica da quitosana aconteceu em três estágios: processo de desidratação, decomposição do biopolímero e geração de material carbonizado. Essas três etapas de degradação térmica da quitosana também foi observada por Corazarri et al. ${ }^{[17]}$. Na faixa de temperatura entre 50 e $150^{\circ} \mathrm{C}$, a perda de massa pode ser associada à dessorção da água presente na superfície do polímero. Na faixa entre $150-450{ }^{\circ} \mathrm{C}$ foi observado o processo principal de degradação térmica. Segundo Corazarri et al., ${ }^{[17]}$ nesta etapa ocorre a liberação de $\mathrm{H}_{2} \mathrm{O}, \mathrm{NH}_{3}, \mathrm{CO}, \mathrm{CO}_{2}$ e $\mathrm{CH}_{3} \mathrm{COOH}$. Por fim, na faixa de $450-600{ }^{\circ} \mathrm{C}$ houve a liberação de $\mathrm{CH}_{4}$. A porcentagem da perda de massa das amostras de quitosana em cada estágio da degradação e a massa residual está relatada na Tabela 2.

$\mathrm{O}$ comportamento térmico da blenda $\mathrm{PHB}$ /quitosana, antes e após processos de esterilização térmica ou radiolítica, foi semelhante ao filme de PHB puro. A degradação térmica aconteceu em um único estágio entre 250 e $300^{\circ} \mathrm{C}$ (Figura 15). As amostras não apresentaram massas residuais.

\section{Conclusões}

A avaliação das propriedades morfológicas, mecânicas e térmicas dos filmes de PHB puro, de quitosana pura e das blendas PHB/quitosana após processos de esterilização térmica ou radiolítica, realizada neste trabalho, forneceu algumas conclusões que estão apresentadas a seguir:

Os filmes de quitosana pura apresentaram alterações significativas nas propriedades mecânicas estudadas após esterilização térmica ou radiolítica. Já para os filmes de PHB puro, a esterilização térmica não comprometeu as propriedades mecânicas estudadas, em contrapartida, a esterilização radiolítica degradou completamente os filmes, resultando em filmes altamente quebradiços.

As blendas PHB/quitosana após os processos de esterilização estudados tiveram comportamento semelhante

Tabela 2. Dados obtidos das curvas de TG das amostras de quitosana em estudo.

\begin{tabular}{|c|c|c|c|c|}
\hline \multirow{2}{*}{ Amostras } & \multicolumn{3}{|c|}{ Perda de massa $(\%)$} & \multirow{2}{*}{ Massa residual (\%) } \\
\hline & $1^{\circ}$ estágio $\left(50-50^{\circ} \mathrm{C}\right)$ & $2^{\circ}$ estágio $\left(150-450^{\circ} \mathrm{C}\right)$ & $3^{\circ}$ estágio $\left(450-600^{\circ} \mathrm{C}\right)$ & \\
\hline Quitosana 75 kGy & 10,0 & 43,5 & 3,7 & 42,8 \\
\hline Quitosana ET & 10,0 & 45,3 & 4,3 & 38,3 \\
\hline Quitosana pura & 9,0 & 42,7 & 3,6 & 44,7 \\
\hline
\end{tabular}

ET - Esterilizado termicamente. 
ao filme de PHB puro. Isso mostrou que a quitosana não alterou as propriedades mecânicas das blendas.

Com base no MEV foi possível observar na blenda a presença de grânulos, referentes à quitosana, dispersos na matriz de PHB. Também foi observado que após esterilização térmica, a blenda apresentou uma superfície rugosa, com a presença de grânulos e alguns vazios na matriz. Já após a esterilização radiolítica, a blenda apresentou-se lisa e homogênea.

A porcentagem de quitosana adicionada e o processo de esterilização térmica não alteraram a temperatura e entalpia de cristalização, a temperatura de fusão e o grau de cristalinidade das blendas, porém as blendas irradiadas com doses de 50 e 75 kGy apresentaram uma redução no valor da entalpia de cristalização, no grau de cristalinidade, na cristalinidade relativa e na taxa de cristalização do filme de PHB/quitosana, além disso, apresentaram dois picos de cristalização.

O comportamento térmico das blendas, antes e após processos de esterilização térmica ou radiolítica, observado pelas curvas de TGA foi semelhante ao comportamento térmico do filme de PHB puro.

Diante destas conclusões, foi notório que o PHB é muito mais determinante nas propriedades das blendas do que a quitosana e que a blenda estudada apresenta uma viabilidade comercial em processos que exijam apenas a esterilização térmica.

\section{Agradecimentos}

Os autores agradecem à PHB industrial S.A. (Brasil) pelo fornecimento do $\mathrm{PHB}$, à Agência Nacional do Petróleo, Gás Natural e Biocombustíveis - ANP e à Financiadora de Estudos e Projetos - FINEP - por meio do Programa de Recursos Humanos da ANP para o Setor de Petróleo e Gás - PRH-ANP/MCT, em particular ao PRH 28 pelo apoio financeiro.

\section{Referências}

1. Faria,A. U., \& Franchetti, S. M. M. (2010). Biodegradação de Filmes de Polipropileno (PP), Poli(3-hidroxibutirato) (PHB) e Blenda de PP/PHB por Micro-organismos das Algas do Rio Atibaia. Polímeros: Ciência e Tecnologia, 20(2), 141-147. http://dx.doi.org/10.1590/S0104-14282010005000024.

2. Wang, C. Q., Wang, H., \& Liu, Y. N. (2015). Separation of polyethylene terephthalate from municipal waste plastics by froth flotation for recycling industry. Waste Management, 35, 42-47. PMid:25449606. http://dx.doi.org/10.1016/j. wasman.2014.09.025.

3. Casarin, S. A., Agnelli, J. A. M., Malmonge, S. M., \& Rosário, F. (2013). Blendas PHB/copoliésteres biodegradáveis: biodegradação em solo. Polímeros: Ciência e Tecnologia, 23(1), 115-122.

4. Franchetti, S. M. M., \& Marconato, J. C. (2006). Polímeros biodegradáveis: uma solução parcial para diminuir a quantidade de resíduos plásticos. Química Nova, 29(4), 811-816. http:// dx.doi.org/10.1590/S0100-40422006000400031.

5. Rosa, D. S., \& Pantano Filho, R. (2003). Biodegradação um ensaio com polímeros. São Paulo: Moara.
6. American Society for Testing and Materials-ASTM. (2012). ASTM 6400-12: standard specification for compostable plastics. West Conshohocken: ASTM.

7. Chodak, I. (2008). Polyhydroxyalkanoates: origin, properties and application. In M. N. Belgacem \& A. Gandini, Monomers, polymers and composites from renewable resources (pp. 451477). Amsterdam: Elsevier.

8. Fechine, G. J. M.(2013). Polímeros biodegradáveis: tipos, mecanismo, normas e mercado mundial. São Paulo: Mackenzie.

9. Peniche, C., Argüeles-Monal, W., \& Goycoolea, F. M. (2008). Chitin and chitosan: major sources, properties and applications. In M. N. Belgacem \& A. Gandini, Monomers, polymers and composites from renewable resources (pp. 517-542). Amsterdam: Elsevier.

10. Abdelwahab, M. A., Flynn, A., Chiou, B. S., Imam, S., Orts, W., \& Chiellini, E. (2012). Thermal, mechanical and morphological characterization of plasticized PLA-PHB blends. Polymer Degradation \& Stability, 97(9), 1822-1828. http://dx.doi. org/10.1016/j.polymdegradstab.2012.05.036.

11. Grande, R., Pessan, L. A., \& Carvalho, A. J. R. (2015). Ternary melt blends of poly(lactic acid)/poly(vinyl alcohol)-chitosan. Industrial Crops and Products, 72, 159-165. http://dx.doi. org/10.1016/j.indcrop.2014.12.041.

12. Malheiro, V. N., Caridade, S. G., Alves, N. M., \& Mano, J. F. (2010). New poly( $\varepsilon$-caprolactone/chitosan blend fibers for tissue engineering applications. Acta Biomaterialia, 6(2), 418-428. PMid:19607943. http://dx.doi.org/10.1016/j.actbio.2009.07.012.

13. Matet, M., Heuzey, M. C., Ajji, A., \& Sarazin, P. (2015). Plasticized chitosan/polyolefin films produced by extrusion. Carbohydrate Polymers, 117, 177-184. PMid:25498623. http:// dx.doi.org/10.1016/j.carbpol.2014.09.058.

14. Carvalho, M. M. S. G., Stamford, T. C. M., Santos, E. P., Tenório, P., \& Sampaio, F. (2011). Chitosan as na oral antimicrobial agent. In A. Méndez-Vilas. Science against microbial pathogens: communicating current research and technological advances (pp. 542-550, Microbiology Series, Vol. 3). Spain: FORMATEX.

15. American Society for Testing and Materials-ASTM. (2012). ASTM D882-12: standard test method for tensile properties of thin plastic sheeting. West Conshohocken: ASTM.

16. Wellen, R. M. R., Rabello, M. S., Fechine, G. J. M., \& Canedo, E. L. (2013). The melting behavior of poly(3-hydroxybutyrate) by DSC. Reproducibility study. Polymer Testing, 32(2), 215220. http://dx.doi.org/10.1016/j.polymertesting.2012.11.001.

17. Corazzari, I., Nisticò, R., Turci, F., Faga, M. G., Franzoso, F., Tabasso, S., \& Magnacca, G. (2015). Advanced physicochemical characterization of chitosan by means of TGA coupled on-line with FTIR and GCMS: Thermal degradation and water adsorption capacity. Polymer Degradation \& Stability, 112, 1-9. http://dx.doi.org/10.1016/j.polymdegradstab.2014.12.006.

18. Machado, M. L. C., Pereira, N. C., Miranda, L. F., \& Terence, M. C. (2010). Estudo das propriedades mecânicas e térmicas do polímero Poli-3-hidroxibutirato (PHB) e de compósitos PHB/pó de madeira. Polímeros: Ciência e Tecnologia, 20(1), 65-71. http://dx.doi.org/10.1590/S0104-14282010005000011.

19. D’Amico, D. A., Manfredi, L. B., \& Cyras, V. P. (2012). Crystallization behavior of poly(3-hydroxybutyrate) nanocomposites based on modified clays: effect organic modifiers. Thermochimica Acta, 544, 47-53. http://dx.doi. org/10.1016/j.tca.2012.06.012.

Enviado: Maio 19, 2015

Revisado: Nov. 15, 2015

Aceito: Dez. 15, 2015 